\title{
内蒙古森林生态系统碳储量及其空间分布
}

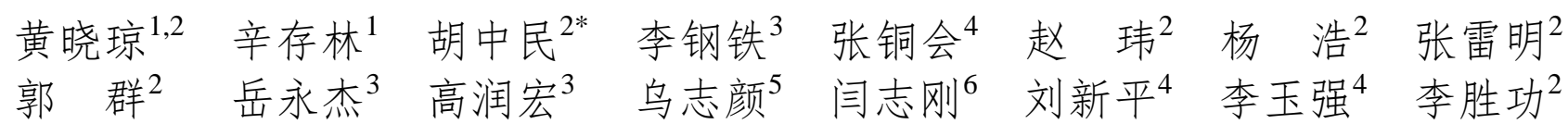

${ }^{1}$ 西北师范大学地理与环境科学学院, 兰州 $730070 ;{ }^{2}$ 中国科学院地理科学与资源研究所生态系统观测与模拟实验室, 北京 $100101 ;{ }^{3}$ 内蒙古农业大学 生态环境学院, 呼和浩特 010018; ${ }^{4}$ 中国科学院寒区早区环境与工程研究所, 兰州 730000; ${ }^{5}$ 赤峰市林业科学研究院, 内蒙古赤峰 $024000 ;{ }^{6}$ 内蒙古大 兴安岭林业科学技术研究所, 内蒙古牙克石 022150

摘 要 内蒙古森林面积居全国第一位, 林木蓄积量居第五位, 准确地估算该区域森林碳储量对于评估中国森林碳储量以及 制定森林资源管理措施均具有重要意义。该研究基于内蒙古森林资源野外样方调查和室内分析, 评估了内蒙古森林生态系统 的固碳现状, 估算了内蒙古森林生态系统不同林型和不同碳库(乔木、灌木、草本、调落物和土壤碳库)的碳密度大小, 揭示 了其空间分布特征。在此基础上估算了内蒙古森林碳储量大小及空间格局。结果表明: 1)内蒙古森林植被层碳储量为 $787.8 \mathrm{Tg}$ C, 乔木层、调落物层、草本层和灌木层分别占植被层总碳储量的 $93.5 \% 、 3.0 \% 、 2.7 \%$ 和 $0.8 \%$ 。内蒙古森林植被层平均碳密 度为 $40.4 \mathrm{t} \cdot \mathrm{hm}^{-2}$, 其中, 乔木层、调落物层、草本层和灌木层的碳密度分别为 $35.6 \mathrm{t} \cdot \mathrm{hm}^{-2} 、 2.9 \mathrm{t} \cdot \mathrm{hm}^{-2} 、 1.2 \mathrm{t} \cdot \mathrm{hm}^{-2}$ 和 $0.6 \mathrm{t} \cdot \mathrm{hm}^{-2}$ 。 2)内蒙古森林土壤层 $(0-100 \mathrm{~cm})$ 碳储量为 $2449.6 \mathrm{Tg}$ C, 其中 $0-30 \mathrm{~cm}$ 的土壤碳储量最高, 占总碳储量的 $79.8 \%$ 。0-10 cm、10-20 $\mathrm{cm}$ 和 $20-30 \mathrm{~cm}$ 的土壤碳储量分别占0-30 $\mathrm{cm}$ 土壤碳储量的 $38.8 \% 、 34.1 \%$ 和 $27.1 \%$ 。内蒙古森林土壤平均碳密度为 $144.4 \mathrm{t} \cdot \mathrm{hm}^{-2}$ 。 黑桦(Betula davurica) 林土壤碳密度最高, 云杉(Picea asperata) 林最小。土壤碳密度随土壤深度的增加而降低。3)内蒙古森林 生态系统碳储量为3 $237.4 \mathrm{Tg}$ C, 植被层和土壤层碳储量分别占森林生态系统碳储量的 $24.3 \%$ 和 $75.7 \%$ 。落叶松(Larix gmelinii) 林总碳储量最高, 其次为白桦(Betula platyphylla)林、夏栋(Quercus robur)林、黑桦林、榆树(Ulmus pumila)疏林和山杨(Populus davidiana)林。内蒙古森林生态系统平均碳密度为 $184.5 \mathrm{t} \cdot \mathrm{hm}^{-2}$ 。土壤碳密度与植被碳密度呈显著正相关关系。4)内蒙古森林 生态系统碳储量和碳密度的空间分布总体上为东部地区高、西部地区低的趋势。在降水量充沛的东部地区和降水偏少的中西 部地区, 有针对性地开展森林保护区建设和人工造林, 可显著提升区域的碳汇能力。

关键词 碳储量; 碳密度; 空间分布; 森林生态系统; 内蒙古

引用格式: 黄晓琼, 辛存林, 胡中民, 李钢铁, 张铜会, 赵玮, 杨浩, 张雷明, 郭群, 岳永杰, 高润宏, 乌志颜, 间志刚, 刘新平, 李玉强, 李胜功 (2016). 内蒙古森林生态系统碳储量及其空间分布. 植物生态学报, 40, 327-340. doi: 10.17521/cjpe.2015.1088

\section{Carbon storage of the forests and its spatial pattern in Nei Mongol, China}

HUANG Xiao-Qiong ${ }^{1,2}$, XIN Cun-Lin ${ }^{1}$, HU Zhong-Min ${ }^{2 *}$, LI Gang-Tie ${ }^{3}$, ZHANG Tong-Hui ${ }^{4}$, ZHAO Wei ${ }^{2}$, YANG Hao $^{2}$, ZHANG Lei-Min ${ }^{2}$, GUO Qun ${ }^{2}$, YUE Yong-Jie ${ }^{3}$, Gao Run-Hong ${ }^{3}$, WU Zhi-Yan ${ }^{5}$, YAN Zhi-Gang ${ }^{6}$, LIU Xin-Ping ${ }^{4}$, LI Yu-Qiang ${ }^{4}$, and LI Sheng-Gong ${ }^{2}$

${ }^{1}$ Department Geography and Environmental Sciences, Northwest Normal University, Lanzhou 730070, China; ${ }^{2}$ Laboratory of Ecosystem Network Observation and Modeling, Institute of Geographic Sciences and Natural Resources Research, Chinese Academy of Sciences, Beijing 100101, China; ${ }^{3}$ College of Ecology and Environmental Science, Inner Mongolia Agricultural University, Hohhot 010018, China; ${ }^{4}$ Cold and Arid Regions Environmental and Engineering Research Institute, Chinese Academy of Sciences, Lanzhou 730000, China; ${ }^{5}$ Chifeng Institute of Forestry Science, Chifeng, Nei Mongol 024000, China; and ${ }^{6}$ Daxing'anling Academy of Forestry Science of Inner Mongolia, Yakeshi, Nei Mongol 022150, China

\section{Abstract}

Aims Forest carbon storage in Nei Mongol plays a significant role in national terrestrial carbon budget due to its large area in China. Our objectives were to estimate the carbon storage in the forest ecosystems in Nei Mongol and to quantify its spatial pattern.

Methods Field survey and sampling were conducted at 137 sites that distributed evenly across the forest types in the study region. At each site, the ecosystem carbon density was estimated thorough sampling and measuring different pools of soil $(0-100 \mathrm{~cm})$ and vegetation, including biomass of tree, grass, shrub, and litter. Regional carbon storage was calculated with the estimated carbon density for each forest type.

Important findings Carbon storage of vegetation layer in forests in Nei Mongol was 787.8 $\mathrm{Tg} \mathrm{C}$, with the biomass of tree, litter, herbaceous and shrub accounting for $93.5 \%, 3.0 \%, 2.7 \%$ and $0.8 \%$, respectively. Carbon 
density of vegetation layer was $40.4 \mathrm{t} \cdot \mathrm{hm}^{-2}$, with $35.6 \mathrm{t} \cdot \mathrm{hm}^{-2}$ in trees, $2.9 \mathrm{t} \cdot \mathrm{hm}^{-2}$ in litter, $1.2 \mathrm{t} \cdot \mathrm{hm}^{-2}$ in herbaceous and $0.6 \mathrm{t} \cdot \mathrm{hm}^{-2}$ in shrubs. In comparison, carbon storage of soil layer in forests in Nei Mongol was $2449.6 \mathrm{Tg}$ C, with $79.8 \%$ distributed in the first $30 \mathrm{~cm}$. Carbon density of soil layer was $144.4 \mathrm{t} \cdot \mathrm{hm}^{-2}$. Carbon storage of forest ecosystem in Nei Mongol was $3237.4 \mathrm{Tg}$ C, with vegetation and soil accounting for $24.3 \%$ and $75.7 \%$, respectively. Carbon density of forest ecosystems in Nei Mongol was $184.5 \mathrm{t} \cdot \mathrm{hm}^{-2}$. Carbon density of soil layer was positively correlated with that of vegetation layer. Spatially, both carbon storage and carbon density were higher in the eastern area, where the climate is more humid. Forest reserves and artificial afforestations can significantly improve the capacity of regional carbon sink.

Key words carbon storage; carbon density; spatial distribution; forest ecosystems; Nei Mongol

Citation: Huang XQ, Xin CL, Hu ZM, Li GT, Zhang TH, Zhao W, Yang H, Zhang LM, Guo Q, Yue YJ, Gao RH, Wu ZY, Yan ZG, Liu XP, Li YQ, Li SG (2016). Carbon storage of the forests and its spatial pattern in Nei Mongol, China. Chinese Journal of Plant Ecology, 40, 327-340. doi: 10.17521/cjpe.2015.1088

森林生态系统作为陆地生态系统最大的碳库, 不仅自身通过物质和能量循环维持着巨大的碳库, 而且还吸收约 $33 \%$ 由人类活动排放的碳, 在调节全 球碳平衡和减缓大气中温室气体浓度上升等方面具 有重要的作用 (Schimel et al., 2001; Houghton, 2007)。为了有效地减少温室气体排放、减缓全球变 暖进程, 有必要明确主要森林分布区碳库的现状 (Pan et al., 2011; 郭纯子等, 2014)。

中国森林生态系统碳储量在全球碳循环和碳平 衡中具有重要地位。内蒙古是中国森林主要分布地 区, 第7次森林资源清查结果显示, 内蒙古森林面积 2487.9 万 $\mathrm{hm}^{2}$, 活立木总蓄积量 14.9 亿 $\mathrm{m}^{3}$, 森林覆 盖率 $21.0 \%$, 森林面积居全国第一位, 林木蓄积量 居全国第五位, 因而准确地估算该地区森林碳储量 对评估中国森林碳储量以及制定森林资源管理措施 具有重要意义。目前关于内蒙古森林碳储量的研究 已有一些报道, 如: 王效科等(2001)估算内蒙古森 林生态系统植被碳拒量为377.6 Tg C; 问德仁和乐 林(2010)估算内蒙古森林碳储量为920.2 Tg C; 昭日 格等(2011)的研究表明: 1977-1988、1989-1993和 1999-2003年, 内蒙古森林碳储量分别为378.9、 430.4和516.0 Tg C; Li等(2014)的研究表明: 内蒙古 森林碳储量由1949年的417 Tg C增加到2008年的 719 Tg C, 平均每年增加2.8-5.2 Tg C。上述研究对 于揭示内蒙古森林在区域及全国森林固碳中的地位 有着重要贡献, 然而, 目前的研究总体上还存在诸 多不足。首先, 目前大多研究基于森林资源清查资 料估算内蒙古全区森林碳储量。森林资源清查资料 仅涉及森林乔木碳库的碳储量或碳密度及其动态变 化的研究(方精云等, 1996; 间德仁, 2011, 2012; 昭
日格等, 2011), 未包括土壤、林下灌木、草本和凋 落物等碳库, 导致难以全面了解内蒙古全区森林碳 储量的大小与分布特征。土壤是森林生态系统最大 的碳库(吴雅琼等, 2007; 杨浩等, 2014), 土壤碳库 大小与变化将直接影响整个森林生态系统的固碳过 程, 因此揭示内蒙古森林土壤碳库的大小显得尤为 重要。另外, 由于当前研究大多基于森林清查资料 统计结果, 只能简单地给出内蒙古全区或各行政区 碳储量总量，而难以描述其空间分布格局。其次， 目前多数研究采用单一的生物量-蓄积量的线性模 型估算乔木层的生物量(Fang et al., 2001)。由于此模 型只是一种简单的线性关系, 估算结果的准确性尚 有争议(王玉辉等, 2001; 王效科等, 2001; Zhang \& Xu, 2002; 赵敏和周广胜, 2004a; Zhao \& Zhou, 2005; 黄从德, 2008; 王新闯等, 2011)。由于用该方 法估算得到的生物量尚未包括根系部分, 因而对植 被碳库的估算大大偏低。再次, 基于植被生物量计 算碳储量时需要植物各器官的碳含量数据, 当前研 究普遍采用固定的碳含量数值(0.50或 0.45$)$, 然而, 不同树种、不同器官的碳含量存在差异, 同时植物 碳含量在空间上也存在高度的变异性(Laiho \& Laine, 1997; Lamlom \& Savidge, 2003; 黄从德, 2008; 王宁, 2014), 采用单一的碳含量数值无疑将 对估算结果产生一定的不确定性。

针对以往研究的不足, 本研究在内蒙古主要森 林分布区设置了137个野外调查样点, 在每个样点 开展植被、土壤碳库的精细调查, 再进一步结合内 蒙古森林分布图揭示内蒙古所有森林各个碳库的碳 密度大小及其空间分布特征, 在此基础上估算了内 蒙古碳储量及其组成特征。为了准确地估算植被的 
碳储量, 本研究通过文献收集或野外实地伐木调查 获得了内蒙古全区主要树木的树干解析方程。另外, 我们还重点调查了该区森林土壤及林下植被的碳库 大小。本研究旨在回答以下两个科学问题: (1)内蒙 古森林碳储量和碳密度有多大, 各碳库的贡献如 何? (2)内蒙古森林生态系统碳储量主要分布于哪 些地区和林型?

\section{1 研究区概况与研究方法}

\section{1 研究区概况}

内蒙古自治区 $\left(97.68^{\circ}-126.07^{\circ} \mathrm{E}, 37.40^{\circ}-53.38^{\circ}\right.$ $\mathrm{N})$ 地处亚欧大陆内部, 位于我国北部边疆, 东西长 2400 多 km, 南北宽1 700多 km。内蒙古森林面积 2487.9 万 $\mathrm{hm}^{2}$, 活立木总蓄积量 14.8 亿 $\mathrm{m}^{3}$, 森林覆 盖率 $21.0 \%$ 。内蒙古自治区具有明显的温带大陆性 季风气候。年平均气温为 $-5-9{ }^{\circ} \mathrm{C}$, 气温由西南向东 北递减; 年降水量为150-500 mm, 由西南向东北递 增。森林主要分布于大兴安岭、燕山北部、阴山山 脉及贺兰山, 其他山区也有少量分布。森林植被类 型主要有温带落叶阔叶林、寒温带和温带山地针叶 林和温带针叶林。优势树种有落叶松 (Larix gmelinii)、樟子松(Pinus sylvestris var. mongolica)、油松 (Pinus tabulaeformis)、夏栋(Quercus robur)、榆树 (Ulmus pumila)、白华 (Betula platyphylla)、黑桦 (Betula davurica)、小叶杨(Populus simonii)、山杨( $P$. davidiana)、胡杨(P. euphratica) 等。

\section{2 采样点设置}

本研究共设置野外调查样点137个(图1)。每个 样点的具体位置根据不同林型的面积与分布区域确 定。首先根据每个林型在全区森林面积中的权重确 定调查的样点数, 其次, 根据该林型的分布区域确 定在每个盟(市)各林型的调查样点数。最后, 通过咨 询地方林业管理部门各林型的分布情况, 确定每个 样点的具体位置。

\section{3 调查方法}

每个样点设置 3 个重复样方 $(50 \mathrm{~m} \times 20 \mathrm{~m}$ 或 $30 \mathrm{~m}$ $\times 20 \mathrm{~m})$, 样方间距至少 $100 \mathrm{~m}$ 。在布设的样方内, 对 胸径 $\geqslant 5 \mathrm{~cm}$ 的树木进行每木检尺, 记录树种、胸径、 树高, 用枝剪法采集优势树种的叶、枝样品, 在树干 部位进行少许破坏性树干样品采集, 在树根周围任 一边向下 $100 \mathrm{~cm}$ 采集树根样品。在乔木样地对角线 上随机设置 3 个 $2 \mathrm{~m} \times 2 \mathrm{~m}$ 的样方, 记录样方内主要

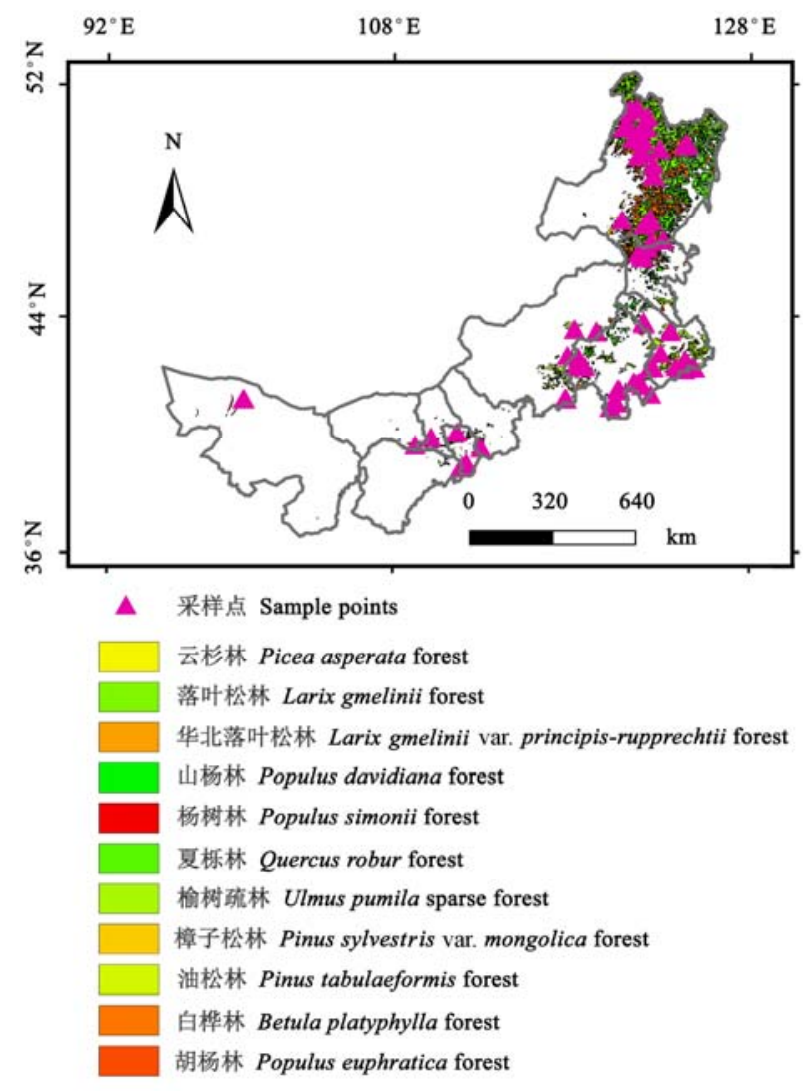

图1 内蒙古森林采样点分布图。

Fig. 1 Distribution of sampling sites in Nei Mongol's forest.

灌木种类及其盖度, 之后将样方内所有植物全部收 获, 分叶、枝、根称定质量。在每个灌木调查样方 内, 围取 1 个 $1 \mathrm{~m} \times 1 \mathrm{~m}$ 的代表性样方, 将样方内所 有草本植物分地上部分和地下部分全部收获，同时 收获样方内的调落物, 烘干后分别测定地上部分、地 下部分和调落物干质量。另外, 在乔木样方内选择3 个未受人为干扰、植被结构和土壤具代表性的地段, 分5个层次 $(0-10 \mathrm{~cm}, 10-20 \mathrm{~cm}, 20-30 \mathrm{~cm}, 30-50 \mathrm{~cm}$, 50-100 cm)采集土壤容重样品和用于养分测定的样 品。共采集植物样品1 957个, 土壤样品1 227个。

\section{4 样品处理}

所有乔木(叶、枝、干、根)、灌木(叶、枝、根)、 草本(地上、地下)和调落物的生物量样品经 $24 \mathrm{~h}$ 、 $65{ }^{\circ} \mathrm{C}$ 烘干至恒质量, 经球磨仪研磨, 过 100 目篮, 用于理化指标分析, 每个样品3个重复。植物样品的 碳含量由元素分析仪(Vario MAX, Elementar, Hanau, Germany)测定。土壤样品自然风干后, 过10目 篮, 即网孔的直径为 $2 \mathrm{~mm}$, 剔除根系和石块, 再用 球磨仪研磨, 过 100 目篮, 取样分析。用重铬酸钾- 
浓硫酸外加热法测定土壤中的有机碳含量。

\section{5 数据处理}

\subsection{1 植被层碳密度的估算}

森林植被层主要由乔木层、灌木层、草本层和 调落物层组成。森林植被碳储量估算采用碳密度乘 以森林分布面积的方法, 森林植被碳密度的估算采 用其各自的生物量乘以碳含量的方法。

在样点尺度上, 乔木的生物量由基于树干解析 方法获取的生物量方程计算得到(附表1)。按叶、枝、 干和根分别计算样方内每株乔木的生物量, 累计叠 加, 除以样地面积, 得到单位面积叶、枝、干和根的 生物量, 再分别乘以实测的叶、枝、干和根的碳含 量, 即得样方内单位面积乔木的碳储量。

$$
\begin{aligned}
D_{T}= & 1 / S_{1} \times\left(W_{\mathrm{L}} \times H_{\mathrm{L}} \times W_{\mathrm{B}} \times H_{\mathrm{B}} \times W_{\mathrm{D}} \times H_{\mathrm{D}} \times W_{\mathrm{R}}\right. \\
& \left.\times H_{\mathrm{R}}\right) \times 100
\end{aligned}
$$

式中, $D_{\mathrm{T}}$ 为乔木层的碳密度 $\left(\mathrm{t} \cdot \mathrm{hm}{ }^{-2}\right), W_{\mathrm{L}} 、 W_{\mathrm{B}} 、 W_{\mathrm{D}}$ 和 $W_{\mathrm{R}}$ 分别为样方内叶、枝、干和根的总生物量 $(\mathrm{kg})$, $H_{\mathrm{L}} 、 H_{\mathrm{B}} 、 H_{\mathrm{D}}$ 和 $H_{\mathrm{R}}$ 分别为叶、枝、干和根的碳含量 $\left(\mathrm{g} \cdot \mathrm{kg}^{-1}\right), S_{1}$ 为样地面积 $\left(\mathrm{m}^{2}\right)$ 。

灌木样方内叶、枝和根的干质量, 除以样方面 积, 再乘以实测的叶、枝和根的碳含量, 加权平均, 即得灌木层的碳密度。草本样方内地上和地下的干 质量, 除以样方面积, 再乘以实测地上和地下的碳 含量, 加权平均, 即得草本层的碳密度。调落物样方 内的干质量, 除以样方面积, 再乘以实测碳含量, 即得调落物层的碳密度。

\subsection{2 土壤层碳密度的估算}

0-10 cm、10-20 cm、20-30 cm、30-50 cm 和 50-100 cm的土壤容重分别乘以实测各层的碳含量, 加权平均, 即得 $0-100 \mathrm{~cm}$ 的土壤碳密度。0-100 cm 单位面积各层土壤碳储量的估算采用碳密度乘以森 林的分布面积, 计算公式为:

$$
D_{\mathrm{S}}=\sum_{K=1}^{5} R_{K} \times H_{K} \times \frac{\theta_{K}}{10}
$$

式中, $D_{\mathrm{S}}$ 为样方内 $0-100 \mathrm{~cm}$ 土壤碳密度 $\left(\mathrm{t} \cdot \mathrm{hm}^{-2}\right), R_{K}$ 和 $H_{K}$ 分别为土壤第 $k$ 层 $(0-10 \mathrm{~cm} 、 10-20 \mathrm{~cm} 、 20-30$ $\mathrm{cm} 、 30-50 \mathrm{~cm}$ 和 $50-100 \mathrm{~cm})$ 的土壤容重 $\left(\mathrm{g} \cdot \mathrm{cm}^{-3}\right)$ 和碳 含量 $\left(\mathrm{g} \cdot \mathrm{kg}^{-1}\right), \theta_{k}$ 为第 $k$ 层采样深度 $(\mathrm{cm})$ 。

\subsection{3 森林生态系统碳储量的估算}

森林生态系统总碳密度是植被层(乔木层、灌木 层、草本层、调落物层) 和土壤层碳密度之和。某一 林型的植被层和土壤层的碳储量为该层的碳密度乘
以相应林型的森林面积。各个碳库的碳储量相加, 即得此林型的碳储量。计算区域尺度森林碳储量, 需用到不同森林类型的分布面积。本研究采用中国 植被覆盖图, 结合中国行政区划图, 提取内蒙古各 盟市的所有林型的森林面积。中国森林分类图反映 的是 20 世纪 80 年代的状况, 与目前的森林分布有一 定差异。提取的森林面积总体上为内蒙古优势树种 的面积, 同时也包括少数除优势种外其他林型的面 积, 而此类林型面积较小, 为减小估算误差, 本文 把其他林型较小的面积合并为相同植被亚类的优势 树种的面积。

\section{2 结果}

\section{1 内蒙古森林植被的碳储量与碳密度}

内蒙古森林植被层碳储量为787.8 $\mathrm{Tg}$ C, 其中 乔木层碳储量最高, 为736.9 $\mathrm{Tg} \mathrm{C}$, 然后依次为调 落物层 $(23.7 \mathrm{Tg}$ C)、草本层 $(21.3 \mathrm{Tg}$ C) 和灌木层 $(6.0$ $\mathrm{Tg}$ C), 分别占植被层总碳储量的 $93.5 \% 、 3.0 \% 、 2.7 \%$ 和 $0.8 \%$ 。不同林型和不同地区植被层碳储量的差异 源于森林的分布面积。森林分布面积最大的落叶松 林植被层碳储量最高, 为416.4 Tg C; 森林分布面 积最小的云杉(Picea asperata) 林植被层碳储量最小, 仅为 $0.1 \mathrm{Tg}$ C (图2A)。呼伦贝尔市的森林分布面积 最大, 其植被层碳储量最高, 为544.6 Tg C, 其中落 叶松林在全市的分布面积最大, 植被层碳储量也最 高, 其次为白华林和夏柇林。鄂尔多斯市的森林面 积最小, 植被层碳储量仅为 $0.7 \mathrm{Tg}$ C (图2B)。

内蒙古森林植被层平均碳密度为 $40.4 \mathrm{t} \cdot \mathrm{hm}^{-2}$, 其中乔木层、调落物层、草本层和灌木层的碳密度 分别为 $35.6 \mathrm{t} \cdot \mathrm{hm}^{-2} 、 2.9 \mathrm{t} \cdot \mathrm{hm}^{-2} 、 1.2 \mathrm{t} \cdot \mathrm{hm}^{-2}$ 和 0.6 $\mathrm{t} \cdot \mathrm{hm}^{-2}$ 。不同林型植被层碳密度差异取决于乔木层 碳密度的大小。人工林和天然林乔木平均碳密度为 33.5 和 $42.9 \mathrm{t} \cdot \mathrm{hm}^{-2}$ 。乔木层碳密度最大的胡杨林植被 层碳密度最高, 为84.3 $\mathrm{t} \cdot \mathrm{hm}^{-2}$, 其次为华北落叶松 (Larix gmelinii var. principis-rupprechtii)林(72.7 $\left.\mathrm{t} \cdot \mathrm{hm}^{-2}\right)$ 、落叶松林 $\left(66.0 \mathrm{t} \cdot \mathrm{hm}^{-2}\right)$ 和白桦林(50.9 $\left.\mathrm{t} \cdot \mathrm{hm}^{-2}\right)$ 。凋落物碳密度最高的为华北落叶松林 $(21.3$ $\left.\mathrm{t} \cdot \mathrm{hm}^{-2}\right)$, 最小的为云杉林 $\left(0.2 \mathrm{t} \cdot \mathrm{hm}^{-2}\right)$ 。草本层碳密度 最大的为黑桦林 (3.3 $\left.\mathrm{t} \cdot \mathrm{hm}^{-2}\right)$, 最小的为杜松 (Juniperus rigida)林 $\left(0.1 \mathrm{t} \cdot \mathrm{hm}^{-2}\right)$, 其中胡杨林内无草 本。灌木层碳密度最高的为夏柇林 $\left(1.1 \mathrm{t} \cdot \mathrm{hm}^{-2}\right)$, 最小 为落叶松林 $\left(0.3 \mathrm{t} \cdot \mathrm{hm}^{-2}\right)$, 其中胡杨林、云杉林、黑桦 


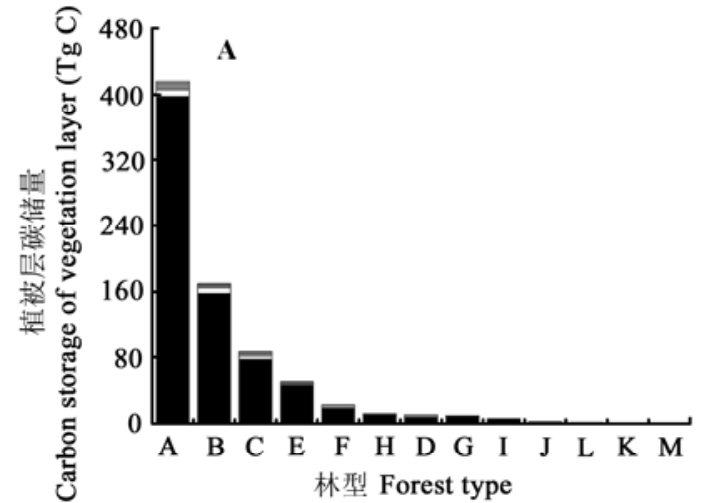

灌木层 Shrub layer

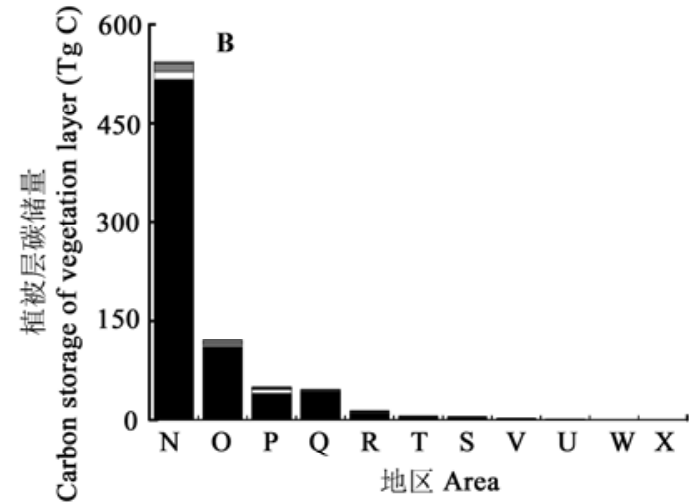

调落物层 Litter layer 乔木层 Tree layer

图2 内蒙古森林不同林型(A)和不同地区(B)的植被碳储量。A, 落叶松林; B, 华北落叶松林; C, 夏栎林; D, 黑桦林; E, 榆树 疏林; F, 山杨林; G, 樟子松林; H, 杨树林; I, 胡杨林; J, 油松林; K, 杜松林; L, 白桦林; $\mathrm{M}$, 云杉林。 N, 呼伦贝尔市; O, 兴安 盟; P, 赤峰市; $\mathrm{Q}$, 通辽市; R, 锡林郭勒盟; $S$, 呼和浩特市; T, 阿拉善盟; U, 包头市; V, 乌兰察布市; W, 巴彦淖尔市; X, 鄂尔 多斯市。

Fig. 2 Carbon storage in different forest types (A) and regions (B) of vegetation layer in Nei Mongol. A, Larix gmelinii forest; B, Larix gmelinii var. principis-rupprechtii forest; C, Quercus robur forest; D, Betula davurica forest; E, Ulmus pumila sparse forest; F, Populus davidiana forest; G, Pinus sylvestris var. mongolica forest; H, Populus simonii forest; I, Populus euphratica forest; J, Pinus tabulaeformis forest; K, Juniperus rigida forest; L, Betula platyphylla forest; M, Picea asperata forest. N, Hulun Buir City; O, Hinggan League; P, Chifeng City; Q, Tongliao City; R, Xilinguole League; S, Hohhot City; T, Alashan League; U, Baotou City; V, Wulanchabu City; W, Bayannur City; X, Ordos City.
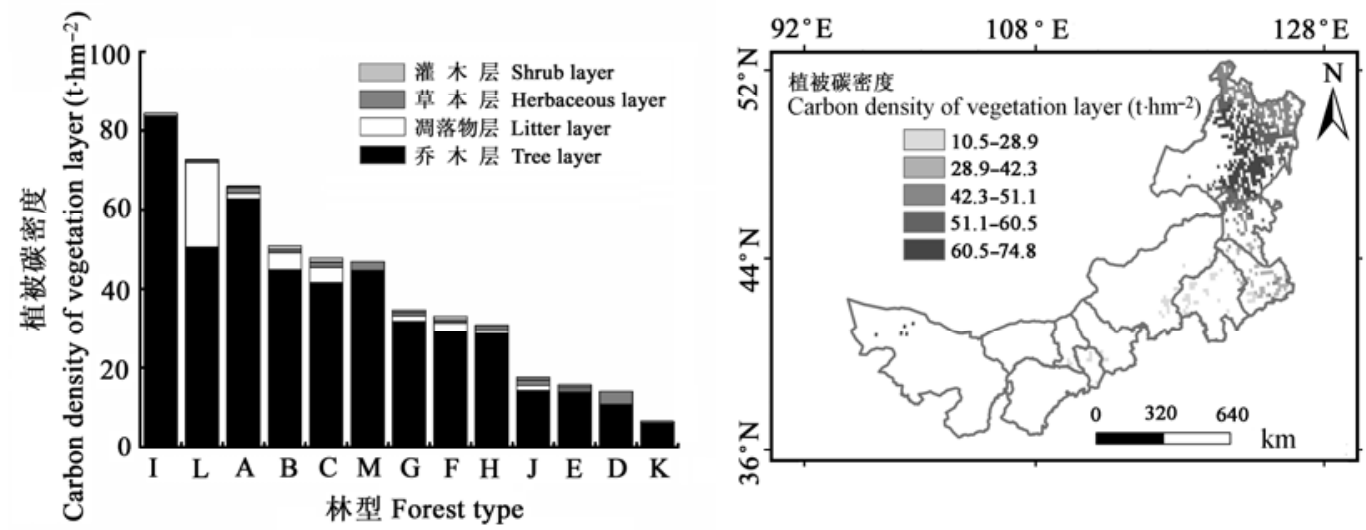

图3 内蒙古森林植被层碳密度及其空间分布。A，落叶松林; B, 华北落叶松林; C, 夏栋林; D, 黑桦林; E, 榆树疏林; F，山杨 林; G，樟子松林; H，杨树林; I，胡杨林; J，油松林; K，杜松林; L，白桦林; M，云杉林。

Fig. 3 Carbon density and its spatial distributions in vegetation layer in forests in Nei Mongol. A, Larix gmelinii forest; B, Larix gmelinii var. principis-rupprechtii forest; C, Quercus robur forest; D, Betula davurica forest; E, Ulmus pumila sparse forest; F, Populus davidiana forest; G, Pinus sylvestris var. mongolica forest; H, Populus simonii forest; I, Populus euphratica forest; J, Pinus tabulaeformis forest; K, Juniperus rigida forest; L, Betula platyphylla forest; M, Picea asperata forest.

林和杜松林无灌木。从空间分布看，内蒙古森林植 被高碳密度区主要集中于东部地区, 即呼伦贝尔东 北部的满归、根河、牙克石、扎兰屯、阿荣旗和兴 安盟的阿尔山、扎㐘特旗、科尔沁右翼前旗等区域 (图3)。

\section{2 内蒙古森林土壤的碳储量与碳密度}

内蒙古森林土壤层 $(0-100 \mathrm{~cm})$ 碳储量为2 449.6
Tg C。0-30 $\mathrm{cm}$ 的土壤碳储量最高, 占总碳储量的 $79.8 \%$ 。0-10 cm、10-20 cm 和 $20-30 \mathrm{~cm}$ 的土壤碳储量 分别占0-30 cm碳储量的 $38.8 \% 、 34.1 \%$ 和 $27.1 \%$ 。就林 型而言, 落叶松林土壤层碳储量最高, 为 $1214.0 \mathrm{Tg}$ C, 其次为白桦林 $(549.1 \mathrm{Tg} \mathrm{C})$ 和夏栋林 $(293.5 \mathrm{Tg}$ C), 这3个林型的碳储量占全区森林土壤总碳储量 的 $84.0 \%$ (图4A)。就区域而言, 呼伦贝尔地区的森林 

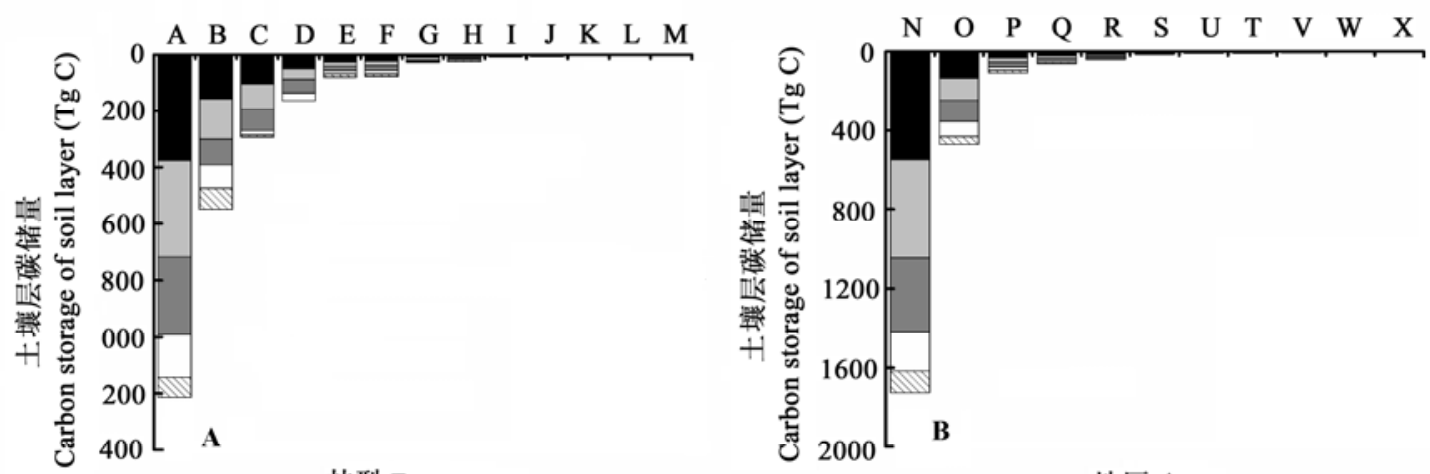

林型 Forest type

土壤深度 Soil depth

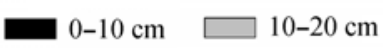

$20-30 \mathrm{~cm} \square 30-50 \mathrm{~cm} \quad 50-100 \mathrm{~cm}$

图4 内蒙古森林不同林型(A)和不同地区(B)的土壤碳储量。A, 落叶松林; B, 华北落叶松林; C, 夏栎林; D, 黑桦林; E, 榆树 疏林; F, 山杨林; G, 樟子松林; H, 杨树林; I, 胡杨林; J, 油松林; K, 杜松林; L, 白桦林; $\mathrm{M}$, 云杉林。 N, 呼伦贝尔市; O, 兴安 盟; P, 赤峰市; $\mathrm{Q}$, 通辽市; R, 锡林郭勒盟; S, 呼和浩特市; $T$, 阿拉善盟; U, 包头市; V, 乌兰察布市; W, 巴彦淖尔市; X, 鄂尔 多斯市。

Fig. 4 Carbon storage in different forest types (A) and regions (B) of soil layer in forests in Nei Mongol. A, Larix gmelinii forest; B, Larix gmelinii var. principis-rupprechtii forest; C, Quercus robur forest; D, Betula davurica forest; E, Ulmus pumila sparse forest; F, Populus davidiana forest; G, Pinus sylvestris var. mongolica forest; H, Populus simonii forest; I, Populus euphratica forest; J, Pinus tabulaeformis forest; K, Juniperus rigida forest; L, Betula platyphylla forest; M, Picea asperata forest. N, Hulun Buir City; O, Hinggan League; P, Chifeng City; Q, Tongliao City; R, Xilinguole League; S, Hohhot City; T, Alashan League; U, Baotou City; V, Wulanchabu City; W, Bayannur City; X, Ordos City.

土壤碳储量最高, 为 $1726.0 \mathrm{Tg}$ C, 其次为兴安盟 (471.0 Tg C)和赤峰市 $(108.0 \mathrm{Tg}$ C), 这3个地区的土 壤碳储量占内蒙古森林土壤碳储量的 $94.1 \%$ 。乌兰 察布、呼和浩特、包头、鄂尔多斯和阿拉善的森林 土壤碳储量较小, 在2.9-13.8 Tg C之间(图4B)。

内蒙古森林土壤 $(0-100 \mathrm{~cm})$ 平均碳密度为 144.4 $\mathrm{t} \cdot \mathrm{hm}^{-2}$, 其中, 黑桦林土壤(0-100 cm)碳密度最高, 为 $252.7 \mathrm{t} \cdot \mathrm{hm}^{-2}$, 云杉林最小为 $33.0 \mathrm{t} \cdot \mathrm{hm}^{-2}$ 。土壤碳密 度随土壤深度的增加而降低, 在0-100 $\mathrm{cm}$ 土壤中, 0-10 $\mathrm{cm}$ 的碳密度最高(图5A)。土壤碳密度的高低与 土壤碳含量有直接的关系。在13种林型中, 土壤碳 含量大多以第一层 $(0-10 \mathrm{~cm})$ 最大, 同样随土壤深度 的增加而降低(图5B)。同一森林类型, 第一层(0-10 $\mathrm{cm}$ )约是第二层 $(10-20 \mathrm{~cm}$ ) 的 0.9-1.8倍 (平均为 1.4 倍); 第二层约是第三层 $(20-30 \mathrm{~cm}$ )的1.0-1.8倍(平 均为1.3倍); 第三层约是第四层 $(30-50 \mathrm{~cm})$ 的1.2-2.3 倍(平均为1.4倍); 第四层约是第五层 $(50-100 \mathrm{~cm})$ 的 0.9-2.0倍(平均为1.5倍) (图5A)。就土壤碳密度的空 间分布特征而言, 土壤高碳密度区主要集中在呼伦 贝尔的南部与兴安盟的北部, 两市接壤的地区, 呼 伦贝尔的东北部的土壤碳密度也较高(图5)。

\section{3 内蒙古森林生态系统的总碳储量与碳密度}

内蒙古全区森林生态系统总碳储量为3 237.4
$\mathrm{Tg}$ C。植被层和土壤层分别占森林生态系统碳储量 的 $24.3 \%$ 和 $75.7 \%$ 。落叶松林总碳储量最高, 占森林 总碳储量的 $50.4 \%$, 其次为白桦林 $(22.2 \%)$ 、夏栎林 (11.8\%)、黑华林(5.4\%)、榆树疏林(4.0\%)、山杨林 (3.1\%), 上述林型的碳储量占总碳储量的 $97.8 \%$ (图 $6 \mathrm{~A})$ 。内蒙古全区森林生态系统碳储量的水平分布 总体上表现为东部地区高, 西部地区低, 和全区森 林面积的分布(东部多、西部少)密切相关。呼伦贝 尔的森林碳储量最高, 占内蒙古森林总碳储量的 $70.1 \%$, 其次分别为兴安盟(18.3\%)、赤峰市 $(4.8 \%)$ 、 通辽市(3.3\%)、锡林郭勒盟(1.7\%), 其他盟市位于内 蒙古中西部，其碳储量仅占总储量的 $1.8 \%$ (图6B)。

内蒙古全区森林生态系统平均碳密度为 184.5 $\mathrm{t} \cdot \mathrm{hm}^{-2}$ 。植被和土壤碳密度分别占总碳密度的 $21.7 \%$ 和 $78.3 \%$ 。各林型碳密度由高到低依次为胡杨林 $\left(286.3 \mathrm{t} \cdot \mathrm{hm}^{-2}\right)$ 、黑桦林 $\left(266.8 \mathrm{t} \cdot \mathrm{hm}^{-2}\right)$ 、落叶松林 $\left(266.8 \mathrm{t} \cdot \mathrm{hm}^{-2}\right)$ 、山杨林 $\left(223.7 \mathrm{t} \cdot \mathrm{hm}^{-2}\right)$ 、白桦林(210.0 $\left.\mathrm{t} \cdot \mathrm{hm}^{-2}\right)$ 、华北落叶松林 $\left(198.3 \mathrm{t} \cdot \mathrm{hm}^{-2}\right)$ 、杨树林 $(180.3$ $\left.\mathrm{t} \cdot \mathrm{hm}^{-2}\right)$ 、夏栋林 $\left(178.6 \mathrm{t} \cdot \mathrm{hm}^{-2}\right) 、$ 杜松林 $\left(161.0 \mathrm{t} \cdot \mathrm{hm}^{-2}\right)$ 、 樟子松林 $\left(132.8 \mathrm{t} \cdot \mathrm{hm}^{-2}\right)$ 、油松林 $\left(113.6 \mathrm{t} \cdot \mathrm{hm}^{-2}\right)$ 、榆树

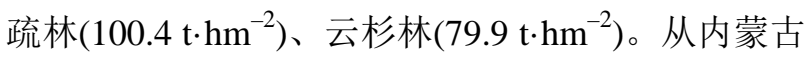
森林生态系统碳密度空间分布图可以看出: 内蒙古 森林生态系统碳密度总体上表现出由东北向西南递 


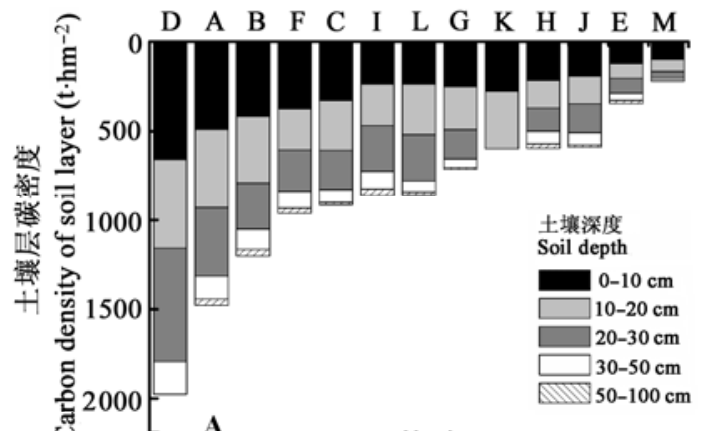

林型

Forest type

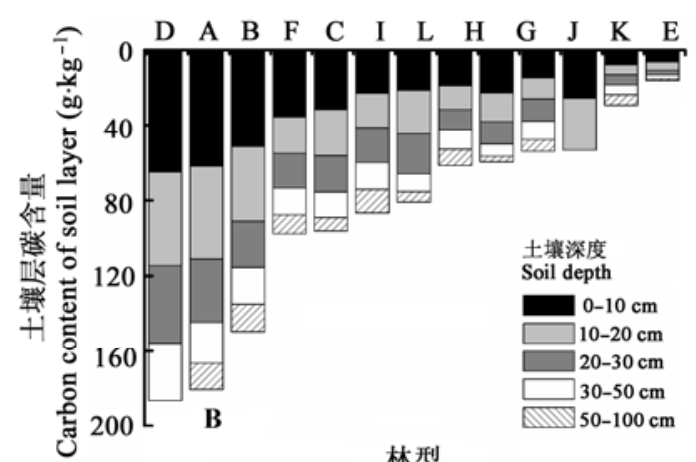

林型

Forest type

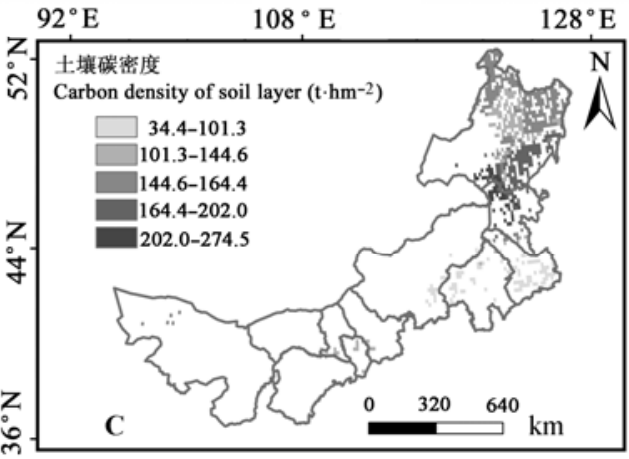

图5 内蒙古森林土壤碳密度 $(A)$ 、碳含量 $(B)$ 及其空间分布 (C)。A, 落叶松林; B, 华北落叶松林; C, 夏栋林; D, 黑桦林; E, 榆树疏林; F, 山杨林; G, 樟子松林; H, 杨树林; I, 胡杨 林; J, 油松林; K, 杜松林; L, 白桦林; $\mathrm{M}$, 云杉林。

Fig. 5 Carbon density (A) and content (B) and their spatial distributions (C) in soil layers in forests in Nei Mongol. A, Larix gmelinii forest; B, Larix gmelinii var. principisrupprechtii forest; C, Quercus robur forest; D, Betula davurica forest; E, Ulmus pumila sparse forest; F, Populus davidiana forest; G, Pinus sylvestris var. mongolica forest; H, Populus simonii forest; I, Populus euphratica forest; J, Pinus tabulaeformis forest; K, Juniperus rigida forest; L, Betula platyphylla forest; M, Picea asperata forest.

减的趋势，其中呼伦贝尔市南部和兴安盟北部的接 壤地区森林碳密度最高, 呼伦贝尔市的根河市、鄂 伦春自治旗、阿荣旗、扎兰屯和牙克石以及兴安盟 的阿尔山市森林碳密度较高(图7)。
土壤碳密度随植被(乔木)碳密度的增加而增加 $(p<0.05)$, 但土壤碳密度随人工林乔木碳密度增加 的趋势要明显于随天然林乔木碳密度增加的趋势 (图8)。森林土壤碳密度和植被碳密度的比值平均为 6.1, 其中云杉林的比值最小, 为 0.7 , 杜松林的比值 最大, 为 23.5 , 这是因为杜松林的土壤碳密度为 $154.5 \mathrm{t} \cdot \mathrm{hm}^{-2}$, 而其植被碳密度仅为 $6.6 \mathrm{t} \cdot \mathrm{hm}^{-2}$ 。

\section{3 讨论}

\section{1 内蒙古森林植被与土壤的碳储量}

内蒙古森林植被层碳储量为787.8 $\mathrm{Tg} \mathrm{C}$, 其中 乔木层占植被层碳储量的 $93.5 \%$, 调落物层和草本 层占 $5.7 \%$, 灌木层占 $0.8 \%$, 说明在该研究区灌木层 对碳储量的贡献微弱, 未来在开展该区域碳储量的 调查时, 灌木样方调查弱化亦不会对区域估算的精 度造成显著影响。不同林型植被层碳密度差异取决 于乔木层碳密度的大小, 内蒙古森林乔木层平均碳 密度为 $35.6 \mathrm{t} \cdot \mathrm{hm}^{-2}$, 同一林区的黑龙江省和辽宁省同 期内的森林乔木层平均碳密度为33.4和31.0 $\mathrm{t} \cdot \mathrm{hm}^{-2}$ (焦燕和胡海清, 2005; Yu et al., 2014), 邻近的北京 市和河北省的森林乔木平均碳密度为 22.5 和 10.3 $\mathrm{t} \cdot \mathrm{hm}^{-2}$ (樊登星等, 2008; 毕君等, 2011)。另外, 我国 中部的陕西省、东部的江苏省、中南部的湖南省和 南部的广东省的森林乔木平均碳密度分别为30.9、 25.8、15.9和 $23.1 \mathrm{t} \cdot \mathrm{hm}^{-2}$ (焦秀梅等, 2005; 叶金盛和 余光辉, 2010; 马琪等, 2012; 杨加猛等, 2014), 其 值均明显小于内蒙古森林乔木层平均碳密度, 究其 原因可能是天然林是内蒙古森林碳储量的主要贡献 者, 其林龄结构大多处于成熟林阶段, 且森林乔木 层碳密度随林龄的增长而增长。内蒙古人工林的林 龄结构大多仍处于中龄林阶段(昭日格等, 2011), 且 随着人工林面积的逐年增加, 森林乔木层碳密度的 逐年增大，内蒙古森林生态系统可能将有更大的碳 储量。内蒙古天然林乔木层碳密度大于人工林乔木 层碳密度, 原因主要是呼伦贝尔市、兴安盟和通辽 市一带, 连接着以天然林著称的大兴安岭, 林龄已 进入成熟林阶段, 故其乔木碳密度较高。相比之下, 人工林因培育时间较短, 仍处于中龄林阶段, 故其 碳密度较低。可见, 天然林是目前内蒙古森林碳储 量的主要贡献者, 而随着人工林面积的增大和林龄 的增加, 未来人工林的碳汇功能会更加突出, 将在 内蒙古森林碳汇功能中起重要作用。 

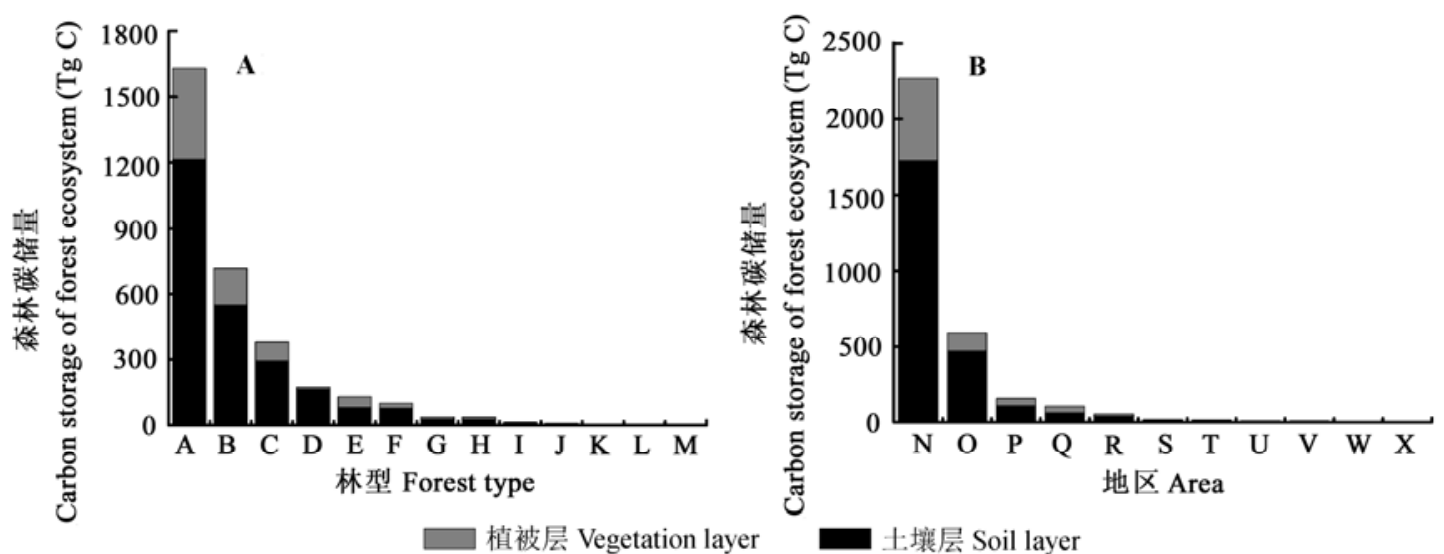

图6 内蒙古森林不同林型(A)和不同地区(B)的碳储量。A, 落叶松林; B, 华北落叶松林; C, 夏栎林; D, 黑桦林; E, 榆树疏林; F, 山杨林; G, 樟子松林; H, 杨树林; I, 胡杨林; J, 油松林; K, 杜松林; L, 白桦林; M, 云杉林。N, 呼伦贝尔市; O, 兴安盟; P, 赤峰市; $\mathrm{Q}$ ，通辽市; R, 锡林郭勒盟; S, 呼和浩特市; T, 阿拉善盟; U, 包头市; V, 乌兰察布市; W, 巴彦淖尔市; X, 鄂尔多斯市。

Fig. 6 Carbon storage in different forest types (A) and regions (B) in forests in Nei Mongol. A, Larix gmelinii forest; B, Larix gmelinii var. principis-rupprechtii forest; C, Quercus robur forest; D, Betula davurica forest; E, Ulmus pumila sparse forest; F, Populus davidiana forest; G, Pinus sylvestris var. mongolica forest; H, Populus simonii forest; I, Populus euphratica forest; J, Pinus tabulaeformis forest; K, Juniperus rigida forest; L, Betula platyphylla forest; M, Picea asperata forest. N, Hulun Buir City; O, Hinggan League; P, Chifeng City; Q, Tongliao City; R, Xilinguole League; S, Hohhot City; T, Alashan League; U, Baotou City; V, Wulanchabu City; W, Bayannur City; X, Ordos City.
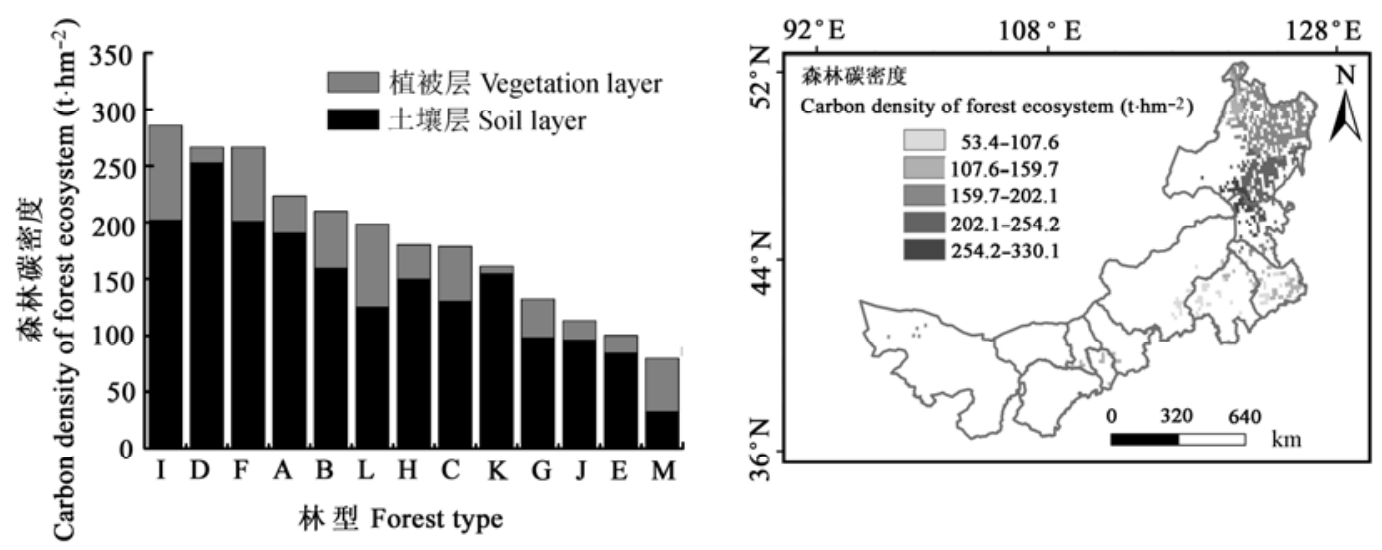

图7 内蒙古森林碳密度及其空间分布。A, 落叶松林; B, 华北落叶松林; C, 夏栎林; D, 黑华林; E, 榆树疏林; F, 山杨林; G, 樟子松林; H，杨树林; I, 胡杨林; J, 油松林; K, 杜松林; L, 白桦林; M, 云杉林。

Fig. 7 Carbon density and its spatial distribution in forests of Nei Mongol. A, Larix gmelinii forest; B, Larix gmelinii var. principis-rupprechtii forest; C, Quercus robur forest; D, Betula davurica forest; E, Ulmus pumila sparse forest; F, Populus davidiana forest; G, Pinus sylvestris var. mongolica forest; H, Populus simonii forest; I, Populus euphratica forest; J, Pinus tabulaeformis forest; K, Juniperus rigida forest; L, Betula platyphylla forest; M, Picea asperata forest.

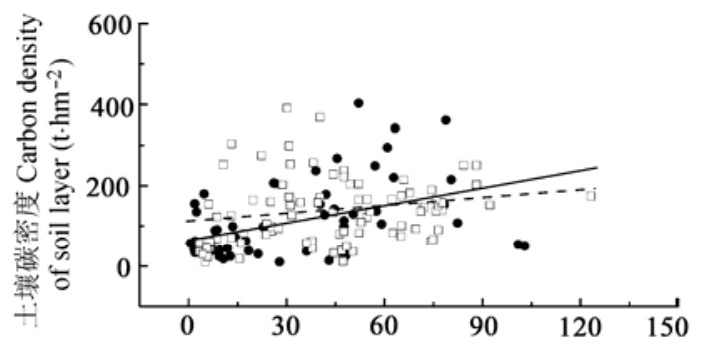

乔木碳密度 Carbon density of tree layer $\left(\mathrm{t} \cdot \mathrm{hm}^{-2}\right)$

- 人工林 Artificial forest

一 人工林 Artificial forest $\left(R^{2}=0.16, p<0.05\right)$

口天然林 Natural forest

- 天然林 Natural forest

$\left(R^{2}=0.06, p<0.05\right)$

图8 内蒙古森林土壤层与乔木层碳密度的关系。

Fig. 8 The relationship between carbon density of soil and tree in forests in Nei Mongol.
内蒙古森林土壤平均碳密度为 $144.4 \mathrm{t} \cdot \mathrm{hm}^{-2}$, 与 齐光等(2013)研究的大兴安岭落叶松林、杨金艳和 王传宽(2005)研究的小兴安岭天然次生林、Zhou等 (2011)研究的长白山老龄林的土壤碳密度的结果相 似, 均明显高于我国森林土壤平均碳密度 107.8 $\mathrm{t} \cdot \mathrm{hm}^{-2}$ (刘世荣等, 2011), 说明内蒙古森林是我国森 林生态系统中重要的土壤碳库。森林土壤是生态系 统中最大的碳库，其储存的碳约是乔木碳库的 1.7-8.8倍(周玉荣等, 2000; 黄从德，2008; 王新闯 等, 2011; 高阳等, 2014; 王宁, 2014)。本研究也表现 出土壤碳库最大, 约是乔木碳库的3.8倍。其中, 土 
壤碳储量随土壤深度的增加而减少。表层土壤(0-10 $\mathrm{cm}$ )碳储量最大, 占0-30 cm土壤碳储量的 $38.8 \%$ 。但 表层土壤的稳定性较差, 易受各种人类活动的影响, 决定了森林土壤碳库是“碳源”还是“碳汇” (黄宇等, 2005; 张城等, 2006)。因此, 减少各种人类活动对表 层土壤的破坏, 加强森林乔木、林下灌木、草本和 调落物对表层土壤的保护, 对增加和维持土壤碳库 的大小以及缓解大气 $\mathrm{CO}_{2}$ 浓度的上升具有重要意 义。落叶松林、白桦林、夏柇林、黑华林、榆树林、 山杨林和杨树林的土壤碳储量较高, 特别是呼伦贝 尔市的落叶松林和白桦林、兴安盟的黑桦林、落叶 松林和白桦林, 通辽市的榆树林、赤峰市的夏柇林、 白桦林和山杨林、锡林郭勒市的杨树林和榆树林是 内蒙古森林土壤碳储量的主要贡献者, 因此加强保 护上述林型, 减少森林砍伐和人为破坏, 对于维持 和提高土壤碳截存具有重要意义。

\section{2 内蒙古森林生态系统碳储量与碳密度}

内蒙古森林生态系统碳储量为3 $237.4 \mathrm{Tg} \mathrm{C}$, 乔木层和土壤层碳储量分别为787.8 Tg C和2 449.6 Tg C。周玉荣等(2000)估测我国森林生态系统碳储 量为28.1 Pg C, 其中乔木层和土壤层碳储量分别为 6.2 Pg C和21.0 Pg C。内蒙古森林分布面积居全国第 一, 其森林生态系统碳储量、乔木层碳储量和土壤 层碳储量均大于同期内位于东北林区的吉林省(王 新闯等, 2011)和西南林区的四川省(黄从德, 2008)。 本研究结果进一步说明, 内蒙古森林生态系统碳储 量在全国森林碳储量中起着举足轻重的作用。

内蒙古森林碳储量和碳密度的分布均表现出东 部地区高、西部地区低的趋势, 这是因为东部地区 降水充沛, 西部地区除河套平原外, 大部分地区属 内陆干旱少雨地带, 植被类型以草地为主。降水和 气温是影响生态系统碳储量和碳密度分布的关键因 素(吕超群和孙书存, 2004; Zhao \& Zhou, 2004; 黄 从德等, 2009), 植被碳储量随降水的增加而增加, 随气温的增加而减少(赵敏和周广胜, 2004b)。内蒙 古森林面积的 $77.3 \%$ 分布在东部地区, 其杨树林、黑 桦林、落叶松林、樟子松林和白华林的碳密度较高, 而夏栋林的碳密度较低。因此, 在降水量充沛的东 部地区, 结合退耕还林工程和天然林保护工程进行 杨树林、黑华林、落叶松林、樟子松林和白桦林的 保护和重建, 将在很大程度上提高内蒙古森林的固 碳潜力。其次, 内蒙古森林面积的 $19.4 \%$ 分布在中部
地区，其白桦林、山杨林、华北落叶松林和夏栎林 的森林碳密度较高, 而云杉林和榆树疏林的森林碳 密度较低, 所以在干旱半干旱的中部地区, 种植白 桦林、山杨林、华北落叶松林和夏栎林, 可提高中 部地区的碳汇能力。内蒙古西部地区的森林面积仅 占3.3\%, 其中胡杨林的森林碳密度最高, 原因可能 是其分布在自然保护区内, 人类活动干扰少, 加之 胡杨林的根系发达, 抗旱能力强, 故其碳密度最高, 所以在干旱的西部地区, 通过种植耐旱树种或建立 保护区的方式, 可提高西部地区的森林碳汇能力。 另外, 在局部地区, 人类活动的干扰程度可能是决 定区域森林碳储量和碳密度分布的主要因素之一。

\section{3 内蒙古森林生态系统碳储量估算的不确定性}

本研究基于野外样方调查数据, 计算了内蒙古 全区主要林型的土壤、乔木、灌木、草本和调落物 的碳密度, 在此基础上估算了全区的森林碳储量。 在估算乔木层碳密度时, 基于生物量方程来估算树 木的生物量。而在选择生物量方程时, 虽然遵守树 木生长的气候因素和土壤因素尽可能相同的原则, 但其准确性与在研究区样地上通过砍伐标准木所建 立的生物量方程有一定的差距(郭纯子等, 2014)。因 而基于文献调研获得的生物量方程是估算乔木生物 量结果不确定性的因素之一。增加生物量解析方程 的基础工作将是降低这一不确定性的核心途径。其 次, 由于研究区森林清查数据难以获取, 本研究在 估算区域碳储量时，不同林型面积的估算依据中国 森林植被覆盖图。该图是基于20世纪80年代的考察 制作而成的，随着时间的推移，部分植被类型的面 积或林型已发生改变, 这将为本研究估算结果带来 一定误差。未来的研究需要在研究区森林分布空间 格局与面积信息获取方面开展深入的工作。第三, 尽管本研究采样点包括了研究区大部分林型, 涵盖 了主要森林分布区, 但仍有少量林型因分布面积小 而没有设置采样点, 这也会对碳密度空间分布和碳 储量的估算造成较微弱的影响。

基金项目 中国科学院战略性先导科技专项(XDA05050201)、中国科学院地理科学与资源研究所青年 人才项目(2013RC203)和科技部科技支撑项目(2013BAC03B03)。

\section{参考文献}

Bi J, Wang C, Li LD, Shi J (2011). Estimation of forest carbon storage in Hebei Province based on IPCC method. Journal 
of Northeast Forestry University, 39(12), 36-38. (in Chinese with English abstract) [毕君, 王超, 李联地, 史靖 (2011). 基于IPCC的河北省2005年森林碳储量. 东北林 业大学学报, 39(12), 36-38.]

Fan DX, Yu XX, Yue YJ, Niu LL, Gao ZL, Ma LY (2008). Forest carbon storage and its dynamics in Beijing. Journal of Beijing Forestry University, 30(S2), 117-120. (in Chinese with English abstract) [樊登星, 余新晓, 岳永杰, 牛 丽丽, 高志亮, 马莉娅 (2008). 北京市森林碳储量及其 动态变化. 北京林业大学学报, 30(S2), 117-120.]

Fang JY, Chen AP, Peng CH, Peng CH, Zhao SQ, Ci LJ (2001). Changes in forest biomass carbon storage in China between 1949 and 1998. Science, 292, 2320-2322.

Fang JY, Liu GH, Xu SL (1996). Biomass and net production of forest vegetation in China. Acta Ecologica Sinica, 16, 497-508. (in Chinese with English abstract) [方精云, 刘 国华, 徐嵩龄 (1996). 我国森林植被的生物量和净生产 量. 生态学报, 16, 497-508.]

Gao Y, Jin JW, Cheng JM, Su JS, Zhu RB, Ma ZR, Liu W (2014). Carbon sequestration status of forest ecosystems in Ningxia Hui Autonomous Region. Chinese Journal of Applied Ecology, 25, 639-646. (in Chinese with English abstract) [高阳, 金晶炜, 程积民, 苏纪帅, 朱仁斌, 马正 锐, 刘伟 (2014). 宁夏回族自治区森林生态系统固碳现 状. 应用生态学报, 25, 639-646.]

Guo CZ, Wu YY, Ni J (2014). Estimation for vegetation carbon storage in Tiantong National Forest Park. Chinese Journal of Applied Ecology, 25, 3099-3109. (in Chinese with English abstract) [郭纯子, 吴洋洋, 倪健 (2014). 天童国家 森林公园植被碳储量估算. 应用生态学报, 25, 30993109.]

Houghton RA (2007). Balancing the global carbon budget. Annual Review of Earth and Planetary Sciences, 35(1), 313-347.

Huang CD (2008). Characteristics of Carbon Stock and Its Spatial Differentiation in the Forest Ecosystem of Sichuan. $\mathrm{PhD}$ dissertation, Sichuan Agricultural University, Ya'an. (in Chinese with English abstract) [黄从德 (2008). 四川 森林生态系统碳储量及其空间分异特征. 博士学位论 文, 四川农业大学, 雅安.]

Huang CD, Zhang J, Yang WQ, Tang X, Zhang GQ (2009). Spatial differentiation characteristics of forest vegetation carbon stock in Sichuan Province. Acta Ecologica Sinica, 29, 5115-5121. (in Chinese with English abstract) [黄从 德, 张健, 杨万勤, 唐宵, 张国庆 (2009). 四川省森林 植被碳储量的空间分异特征. 生态学报，29，51155121.]

Huang Y, Feng ZW, Wang SL, Feng ZZ, Zhang HX, Xu YR (2005). C and N stocks under three plantation forest ecosystems of Chinese-fir, Michelia macclurei and their mix- ture. Acta Ecologica Sinica, 25, 3146-3154. (in Chinese with English abstract) [黄宇, 冯宗炜, 汪思龙, 冯兆忠, 张红星, 徐永荣 (2005). 杉木、火力楠纯林及其混交林 生态系统C、N咜量. 生态学报, 25, 3146-3154.]

Jiao XM, Xiang WH, Tian DL (2005). Carbon storage of forest vegetation and its geographical distribution in Hunan Province. Journal of Central South Forestry University, 25, 4-8. (in Chinese with English abstract) [焦秀梅, 项文 化, 田大伦 (2005). 湖南省森林植被的碳栬量及其地理 分布规律. 中南林学院学报, 25, 4-8.]

Jiao Y, Hu HQ (2005). Carbon storage and its dynamics of forest vegetations in Heilongjiang Province. Chinese Journal of Applied Ecology, 16, 2248-2252. (in Chinese with English abstract) [焦燕, 胡海清 (2005). 黑龙江省 森林植被碳储量及其动态变化. 应用生态学报, 16 , 2248-2252.]

Laiho R, Laine J (1997). Tree stand biomass and carbon content in an age sequence of drained pine mires in southern Finland. Forest Ecology and Management, 93, 161-169.

Lamlom SH, Savidge RA (2003). A reassessment of carbon content in wood: Variation within and between 41 North American species. Biomass and Bioenergy, 25, 381-388.

Li SY, Huang M, Li SG (2014). Forest carbon research in Inner Mongolia: Current knowledge, opportunity and challenge. IOP Conference Series: Earth and Environmental Science, 17, doi: 10.1088/1755-1315/17/1/012011.

Liu SR, Wang H, Luan JW (2011). A review of research progress and future prospective of forest soil carbon stock and soil carbon process in China. Acta Ecologica Sinica, 31, 5437-5448. (in Chinese with English abstract) [刘世 荣, 王晖, 奕军伟 (2011). 中国森林土壤碳储量与土壤 碳过程研究进展. 生态学报, 31, 5437-5448.]

Lü CQ, Sun SC (2004). A review on the distribution patterns of carbon density in terrestrial ecosystems. Acta Phytoecologica Sinica, 28, 692-703. (in Chinese with English abstract) [吕超群, 孙书存 (2004). 陆地生态系统碳密度 格局研究概述. 植物生态学报, 28, 692-703.]

Ma Q, Liu K, Zhang H (2012). Carbon storage by forest vegetation and its spatial distribution in Shaanxi. Resources Science, 34, 1781-1789. (in Chinese with English abstract) [马琪, 刘康, 张慧 (2012). 陕西省森林植被碳储量及 其空间分布. 资源科学, 34, 1781-1789.]

Pan YD, Birdsey RA, Fang JY, Houghton R, Kauppi PE, Kurz WA, Phillips OL, Shvidenko A, Lewis SL, Canadell JG, Ciais P, Jackson RB, Pacala SW, McGuire AD, Piao SL, Rautiainen A, Sitch S, Hayes D (2011). A large and persistent carbon sink in the world's forests. Science, 333, 988-993.

Qi G, Wang QL, Wang XC, Yu DP, Zhou L, Zhou WM, Peng SL, Dai LM (2013). Soil organic carbon storage in different aged Larix gmelinii plantations in Great Xing'an Mountains of Northeast China. Chinese Journal of Applied

www.plant-ecology.com 
Ecology, 24, 10-16. (in Chinese with English abstract) [齐 光, 王庆礼, 王新闯, 于大炮, 周莉, 周旺明, 彭舜磊, 代力民 (2013). 大兴安岭林区兴安落叶松人工林土壤 有机碳咜量. 应用生态学报, 24, 10-16.]

Schimel DS, House JI , Hibbard KA, Bousquet P, Ciais P, Peylin P, Braswell BH, Apps MJ, Baker D, Bondeau A, Canadell J, Churkina G, Cramer W, Denning AS, Field CB, Friedlingstein P, Goodale C, Heimann M, Houghton RA, Melillo JM, Moore III B, Murdiyarso D, Noble I, Pacala SW, Prentice IC, Raupach MR, Rayner PJ, Scholes RJ, Steffen WL, Wirth C (2001). Recent patterns and mechanisms of carbon exchange by terrestrial ecosystems. Nature, 414, 169-172.

Wang N (2014). Study on Distribution Patterns of Carbon Density and Carbon Stock in the Forest Ecosystem of Shanxi. PhD dissertation, Beijing Forestry University, Beijing. (in Chinese with English abstract) [王宁 (2014). 山 西森林生态系统碳密度分配格局及碳储量研究. 博士 学位论文, 北京林业大学, 北京.]

Wang XC, Qi G, Yu DP, Zhou L, Dai LM (2011). Carbon storage, density, and distribution in forest ecosystems in Jilin Province of Northeast China. Chinese Journal of Applied Ecology, 22, 2013-2020. (in Chinese with English abstract) [王新闯, 齐光, 于大炮, 周莉, 代力民 (2011). 吉林省森林生态系统的碳储量、碳密度及其分布. 应用 生态学报, 22, 2013-2020.]

Wang XK, Feng ZW, Ouyang ZY (2001). Vegetation carbon storage and density of forest ecosystems in China. Chinese Journal of Applied Ecology, 12, 13-16. (in Chinese with English abstract) [王效科, 冯宗炜, 欧阳志云 (2001). 中国森林生态系统的植物碳储量和碳密度研究. 应用 生态学报, 12, 13-16.]

Wang YH, Zhou GS, Jiang YL, Yang ZY (2001). Estimating biomass and NPP of Larix forests using forest inventory data (FID). Acta Phytoecologica Sinica, 25, 420-425. (in Chinese with English abstract) [王玉辉, 周广胜, 蒋延玲, 杨正宇 (2001). 基于森林资源清查资料的落叶松林生 物量和净生长量估算模式. 植物生态学报，25，420425.]

Wu YQ, Liu GH, Fu BJ, Guo YH (2007). Soil $\mathrm{CO}_{2}$ efflux of forest ecosystem in China: Distribution and controlling factors. Acta Ecologica Sinica, 27, 2126-2135. (in Chinese with English abstract) [吴雅琼, 刘国华, 傅伯杰, 郭玉华 (2007). 中国森林生态系统土壤 $\mathrm{CO}_{2}$ 释放分布规律及其 影响因素. 生态学报, 27, 2126-2135.]

Yan DR (2011). Forest carbon stock and dynamic change in sandy area in Inner Mongolia. Forest Resources Management, 1, 111-114. (in Chinese with English abstract) [闵德 仁 (2011). 内蒙古沙区森林碳储量及其动态变化. 林业 资源管理, 1, 111-114.]
Yan DR (2012). Forest resources and its carbon stock in Inner Mongolia Sandy areas. Journal of Desert Research, 32(2), 564-567. (in Chinese with English abstract) [闯德仁 (2012). 内蒙古沙区森林及其碳储量估算. 中国沙漠, 32(2), 564-567.]

Yan DR, Le L (2010). Forest carbon storage and its regional change feature in Inner Mongolia. Inner Mongolia Forestry Science and Technology, 36(3), 19-22. (in Chinese with English abstract) [间德仁, 乐林 (2010). 内蒙古森 林碳储量及其区域变化特征. 内蒙古林业科技, 36(3), 19-22.]

Yang H, Hu ZM, Zhang LM, Li SG (2014). Characteristics of carbon storage of Inner Mongolia forests: A review. Chinese Journal of Applied Ecology, 25, 3366-3372. (in Chinese with English abstract) [杨浩, 胡中民, 张雷明, 李胜 功 (2014). 内蒙古森林碳汇特征研究进展. 应用生态学 报, 25, 3366-3372.]

Yang JM, Du LY, Cai ZJ, Zhang ZG (2014). Study on regional distribution of forest carbon storage in Jiangsu Province. Journal of Central South University of Forestry \& Technology, 34(7), 84-89. (in Chinese with English abstract) [杨加猛, 杜丽永, 蔡志坚, 张智光 (2014). 江苏省森林 碳储量的区域分布研究. 中南林业科技大学学报, 34(7), 84-89.]

Yang JY, Wang CK (2005). Soil carbon storage and flux of temperate forest ecosystems in northeastern China. Acta Ecologica Sinica, 25, 2875-2882. (in Chinese with English abstract) [杨金艳, 王传宽 (2005). 东北东部森林生 态系统土壤碳咜量和碳通量. 生态学报, 25, 28752882.]

Ye JS, She GH (2010). Forest carbon dynamics in Guangdong Province. Journal of Nanjing Forestry University (Natural Science Edition), 34(4), 7-12. (in Chinese with English abstract) [叶金盛, 余光辉 (2010). 广东省森林植被碳 储量动态研究. 南京林业大学学报(自然科学版), 34(4), 7-12.]

Yu DP, Wang XY, Yin Y, Zhan JY, Lewis BJ, Tian J, Bao Y, Zhou WM, Zhou L, Dai LM (2014). Estimates of forest biomass carbon storage in Liaoning Province of Northeast China: A review and assessment. PLoS ONE, 9, e89572.

Zhang C, Wang SQ, Yu GR, He HL, Zhang WJ, Wang BL, Chen QM, Wu ZF (2006). Soil organic carbon storage in typical forestland in East China. Resources Science, 28(2), 97-103. (in Chinese with English abstract) [张城, 王绍强, 于贵瑞, 何洪林, 张文娟, 王伯伦, 陈庆美, 吴志峰 (2006). 中国东部地区典型森林类型土壤有机碳储量分 析. 资源科学, 28(2), 97-103.]

Zhang XQ, Xu D (2002). Calculating forest biomass changes in China. Science, 296, 1359.

Zhao M, Zhou GS (2004a). Carbon storage of forest vegetation and its relationship with climatic factors. Scientia Geo- 
graphica Sinica, 24, 50-53. (in Chinese with English abstract) [赵敏, 周广胜 (2004a). 中国森林生态系统的植 物碳咜量及其影响因子分析. 地理科学, 24, 50-53.]

Zhao M, Zhou GS (2004b). Forest Inventory Data (FID)-based biomass models and their prospects. Chinese Journal of Applied Ecology, 15, 1468-1491. (in Chinese with English abstract) [赵敏, 周广胜 (2004b). 基于森林资源清查资 料的生物量估算模式及其发展趋势. 应用生态学报, 15 , 1468-1472.]

Zhao M, Zhou GS (2005). Estimation of biomass and net primary productivity of major planted forests in China based on forest inventory data. Forest Ecology and Management, 207, 295-313.

Zhao RG, Yue YJ, Yao YF, Li GT (2011). Forest carbon storage and its dynamics in Inner Mongolia. Journal of Arid Land Resources and Environment, 25(9), 80-84. (in Chi- nese with English abstract) [昭日格, 岳永杰, 姚云峰, 李 钢铁 (2011). 内蒙古自治区森林碳储量及其动态变化. 干旱区资源与环境, 25(9), 80-84.]

Zhou L, Dai LM, Wang SX, Huang XT, Wang XC, Qi L, Wang QW, Li GW, Wei YW, Shao GF (2011). Changes in carbon density for three old-growth forests on Changbai Mountain, Northeast China: 1981-2010. Annals of Forest Science, 68, 953-958.

Zhou YR, Yu ZL, Zhao SD (2000). Carbon storage and budget of major Chinese forest types. Acta Phytoecologica Sinica, 24, 518-522. (in Chinese with English abstract) [周玉荣, 于振良, 赵士洞 (2000). 我国主要森林生态系统碳咜量 和碳平衡. 植物生态学报, 24, 518-522.]

责任编委: 王根绪 责任编辑: 王 葳 
附录1 优势树种生物量方程

Appendix 1 Biomass equation of dominant tree species

\begin{tabular}{|c|c|c|c|c|}
\hline $\begin{array}{l}\text { 优势种 } \\
\text { Dominant species } \\
\end{array}$ & $\begin{array}{l}\text { 器官 } \\
\text { Organ } \\
\end{array}$ & $\begin{array}{l}\text { 生物量方程 } \\
\text { Biomass equation }\end{array}$ & $R^{2}$ & $\begin{array}{c}\text { 来源 } \\
\text { Source } \\
\end{array}$ \\
\hline 白桦 & 叶 Leaf & $W=0.01175\left(D^{2} H\right)^{0.636}$ & 0.96 & 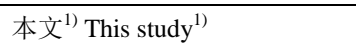 \\
\hline \multirow[t]{3}{*}{ Betula platyphylla } & 枝 Branch & $W=0.02938\left(D^{2} H\right)^{0.663}$ & 0.94 & 本文 $^{1)}$ This study ${ }^{1)}$ \\
\hline & 干 Stem & $W=0.04152\left(D^{2} H\right)^{0.923}$ & 0.99 & 本文 $^{1)}$ This study ${ }^{1)}$ \\
\hline & 根 Root & $W=0.02993\left(D^{2} H\right)^{0.767}$ & 0.95 & 本文 $^{1)}$ This study ${ }^{1)}$ \\
\hline 榆树 & 叶 Leaf & $W=0.019\left(D^{2} H\right)^{0.686}$ & 0.92 & 本文 ${ }^{1)}$ This study ${ }^{1)}$ \\
\hline \multirow[t]{3}{*}{ Ulmus pumila } & 枝 Branch & $W=0.021\left(D^{2} H\right)^{0.847}$ & 0.96 & 本文 $^{1)}$ This study ${ }^{1)}$ \\
\hline & 干 Stem & $W=0.028\left(D^{2} H\right)^{0.929}$ & 0.96 & 本文 ${ }^{1)}$ This study ${ }^{1)}$ \\
\hline & 根 Root & $W=0.646\left(D^{2} H\right)^{0.49}$ & 0.93 & 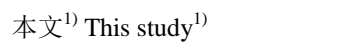 \\
\hline 油松 & 叶 Leaf & $W=0.0134\left(D^{2} H\right)^{0.8539}$ & 0.92 & Fang et al., 2006 \\
\hline Pinus & 枝 Branch & $W=0.0017\left(D^{2} H\right)^{1.1515}$ & 0.94 & Fang et al., 2006 \\
\hline \multirow[t]{2}{*}{ tabulaeformis } & 干 Stem & $W=0.0475\left(D^{2} H\right)^{0.8539}$ & 0.98 & Fang et al., 2006 \\
\hline & 根 Root & $W=0.0027\left(D^{2} H\right)^{1.0917}$ & 0.95 & Fang et al., 2006 \\
\hline 云杉 & 叶 Leaf & $W=\exp \left(-5.94+0.96 \ln \left(D^{2} H\right)\right)$ & 0.98 & Cheng, 2007 \\
\hline \multirow[t]{3}{*}{ Picea asperata } & 枝 Branch & $W=\exp \left(-4.64+0.93 \ln \left(D^{2} H\right)\right)$ & 0.96 & Cheng, 2007 \\
\hline & 干 Stem & $W=\exp \left(-3.97+0.94 \ln \left(D^{2} H\right)\right)$ & 0.99 & Cheng, 2007 \\
\hline & 根 Root & $W=\exp \left(-5.28+0.95 \ln \left(D^{2} H\right)\right)$ & 0.99 & Cheng, 2007 \\
\hline 小叶杨 & 叶 Leaf & $W=0.012\left(D^{2} H\right)^{0.685}$ & 0.96 & Li et al., 2007 \\
\hline \multirow[t]{3}{*}{ Populus simonii } & 枝 Branch & $W=0.001\left(D^{2} H\right)^{1.157}$ & 0.98 & Li et al., 2007 \\
\hline & 干 Stem & $W=0.006\left(D^{2} H\right)^{1.098}$ & 0.99 & Li et al., 2007 \\
\hline & 根 Root & $W=0.083\left(D^{2} H\right)^{0.636}$ & 0.92 & Li et al., 2007 \\
\hline 胡杨 & 叶 Leaf & $W=0.3365197\left(D^{2} H\right)^{1.09391}$ & 0.98 & Wang et al., 2003 \\
\hline \multirow[t]{3}{*}{ Populus euphratica } & 枝 Branch & $W=0.0689471\left(D^{2} H\right)^{0.78924}$ & 0.98 & Wang et al., 2003 \\
\hline & 干 Stem & $W=0.15850279\left(D^{2} H\right)^{0.7058}$ & 0.98 & Wang et al., 2003 \\
\hline & 根 Root & $W=0.427552($ 叶 leaf + 枝 branch + 干 stem) & & Wang et al., 2003 \\
\hline 山杨 & 叶 Leaf & $W=0.031355\left(D^{2} H\right)^{0.658}$ & 0.90 & Jiang et al., 2014 \\
\hline \multirow[t]{3}{*}{ Populus davidiana } & 枝 Branch & $W=0.11921\left(D^{2} H\right)^{0.578}$ & 0.91 & Jiang et al., 2014 \\
\hline & 干 Stem & $W=0.111985 D^{1.702}$ & 0.98 & Jiang et al., 2014 \\
\hline & 根 Root & $W=0.058633\left(D^{2} H\right)^{0.748}$ & 0.95 & Jiang et al., 2014 \\
\hline 黑桦 & 叶 Leaf & $W=0.0079\left(D^{2} H\right)^{0.8085}$ & & Wang et al., 2014 \\
\hline \multirow[t]{3}{*}{ Betula davurica } & 枝 Branch & $W=0.00724\left(D^{2} H\right)^{1.0225}$ & & Wang et al., 2014 \\
\hline & 干 Stem & $W=0.14114\left(D^{2} H\right)^{0.723}$ & & Wang et al., 2014 \\
\hline & 根 Root & $W=0.0616\left(D^{2} H\right)^{0.7892}$ & & Wang et al., 2014 \\
\hline 杜松 & 叶 Leaf & $W=0.0057\left(D^{2} H\right)^{0.7763}$ & 0.936 & 未发表数据 ${ }^{2)}$ Unpublished data $^{2)}$ \\
\hline \multirow[t]{3}{*}{ Juniperus rigida } & 枝 Branch & $W=0.0035\left(D^{2} H\right)^{0.9687}$ & 0.936 & 未发表数据 ${ }^{2}$ Unpublished data $^{2)}$ \\
\hline & 干 Stem & $W=0.0467\left(D^{2} H\right)^{0.8824}$ & 0.936 & 未发表数据 ${ }^{2)}$ Unpublished data ${ }^{2)}$ \\
\hline & 根 Root & $W=0.0318\left(D^{2} H\right)^{0.8229}$ & 0.936 & 未发表数据 ${ }^{2)}$ Unpublished data ${ }^{2)}$ \\
\hline 夏栋 & 叶 Leaf & $W=0.0495 D^{1.84438}$ & 0.95 & Xu et al., 2006 \\
\hline \multirow[t]{3}{*}{ Quercus robur } & 枝 Branch & $W=0.0176 D^{2.65462}$ & 0.94 & Xu et al., 2006 \\
\hline & 干 Stem & $W=0.1069 D^{2.51353}$ & 0.98 & Xu et al., 2006 \\
\hline & 根 Root & $W=2.91599 \mathrm{e}^{0.14465 D}$ & 0.92 & Xu et al., 2006 \\
\hline 樟子松 & 叶 Leaf & $W=\exp (-1.33642+1.05457 \ln D)$ & & Liu et al., 2013 \\
\hline Pinus sylvestris & 枝 Branch & $W=\exp (-2.51434+1.5922 \ln D)$ & & Liu et al., 2013 \\
\hline \multirow[t]{2}{*}{ var. mongolica } & 干 Stem & $W=\exp \left(-1.87871+0.74238 \ln \left(D^{2} H\right)\right)$ & & Liu et al., 2013 \\
\hline & 根 Root & $W=\exp (-1.49632+0.73582 \ln D)$ & & Liu et al., 2013 \\
\hline 落叶松 & 叶 Leaf & $W=0.0078\left(D^{2} H\right)^{0.6701}$ & 0.85 & Wang et al., 2012 \\
\hline
\end{tabular}


附录1 (续) Appendix 1 (continued)

\begin{tabular}{lllll}
\hline $\begin{array}{l}\text { 优势种 } \\
\text { Dominant species }\end{array}$ & $\begin{array}{c}\text { 器官 } \\
\text { Organ }\end{array}$ & $\begin{array}{c}\text { 生物量方程 } \\
\text { Biomass equation }\end{array}$ & $R^{2}$ & $\begin{array}{c}\text { 来源 } \\
\text { Source }\end{array}$ \\
\hline Larix gmelinii & 枝 Branch & $W=0.0213\left(D^{2} H\right)^{0.7165}$ & 0.90 & Wang et al., 2012 \\
& 干 Stem & $W=0.0286\left(D^{2} H\right)^{0.9756}$ & 0.99 & Wang et al., 2012 \\
& 根 Root & $W=0.0164\left(D^{2} H\right)^{0.904}$ & 0.94 & Wang et al., 2012 \\
华北落叶松 & 叶 Leaf & $W=0.0441\left(D^{2} H\right)^{0.5844}$ & 0.86 & Liu, 2012 \\
Larix gmelinii var. & 枝 Branch & $W=0.0386\left(D^{2} H\right)^{0.7492}$ & 0.91 & Liu, 2012 \\
principis-rupprechtii & 干 Stem & $W=0.0462\left(D^{2} H\right)^{0.8647}$ & 0.99 & Liu, 2012 \\
& 根 Root & $W=0.0142\left(D^{2} H\right)^{0.8899}$ & 0.98 & Liu, 2012
\end{tabular}

$\bar{D}$, 胸径 $(\mathrm{cm}) ; H$, 树高 $(\mathrm{m}) ; W$, 生物量 $(\mathrm{kg})$ 。1)根据采集的标准木, 建立白桦和榆树的胸径、树高和各个器官(叶、枝、干、根)的生物量相关系数表, 并 根据相关系数, 选取测树因子 $\left(D^{2} H\right)$ 为预测变量, 建立预测变量和各个生物量之间的生物量方程。2)中国科学院碳专项森林课题, 未发表数据。设置的 样地内除多数为优势树种外, 还有少数的其他树种, 因这些树种没有相关报道的生物量方程, 所以本研究就使用相似优势种的生物量方程, 如山榆和 小叶榆使用榆树的生物量方程, 赤峰杨和赤峰小叶杨使用杨树的生物量方程。还有些树种因数量太少, 就使用相同样地内优势种的生物量方程, 如山 杏和五角枫使用山杨的，枫树、元宝树、色树和椴树使用栎树的生物量方程。

$D$, diameter at breast height $(D B H) ; H$, tree height; $W$, biomass. 1) The establishment of Betula platyphylla and Ulmus pumila DBH, hight and various organs (leaf, branch, stem, root biomass) correlation coefficient table of biomass, was according to the acquired standard woods, and the measurement factor $\left(D^{2} H\right)$ was selected as predictor variables according to the correlation coefficient acquired, established between the predictor variables and the biomass equation of dominant tree species. 2) Special forest project of Chinese Academy of Sciences, unpublished data. Dominant species accounted for the majority of any plots, and other species were part of the minority, because there was no biomass equation of these species reported before, this study will use a similar biomass equation of dominant tree species. Because the number of some species is too small, we used the biomass equation dominant species in the same plot.

\section{参考文献}

Cheng TR (2007). Research on the Forest Biomass and Carbon Storage in Xiaolong Mountains, Gansu Province. PhD dissertation, Beijing Forestry University, Beijing. (in Chinese with English abstract) [程堂仁 (2007). 甘肃小陇山森林生物量及碳储量研究. 博士学位论文, 北京林业大学, 北京.]

Fang JY, Liu GH, Zhu B, Wang XK, Liu SH (2006). Carbon cycle of three temperature forest ecosystems in Dongling Mountain, Beijing. Science in China Series D: Earth Sciences, 36, 533-543. (in Chinese with English abstract) [方精云, 刘国华, 朱彪, 王效科, 刘绍辉 (2006). 北京东灵山三种温带森林 生态系统的碳循环. 中国科学D辑: 地球科学, 36, 533-543.]

Li JH, Li CJ, Peng SK (2007). Study on the biomass expansion factor of poplar plantation. Journal of Nanjing Forestry University (Natural Science Edition), 31(4), 37-40. (in Chinese with English abstract) [李建华, 李春静, 彭世揆 (2007). 杨树人工林生物量估计方法与应用. 南京林业大学学报(自然科学 版), 31(4), 37-40.]

Liu HM, Lü SJ, Liu QQ, Liu LY, Wang YZ, Zhang HB (2013). Biomass and carbon storage of the Pinus sylvestris var. mongolica Litv. plantation in the Duolun County. Journal of Inner Mongolia Agricultural University, 34(3), 49-53. (in Chinese with English abstract) [刘红梅, 吕世杰, 刘清泉, 刘丽英, 王玉芝, 章海波 (2013). 多伦县樟子松人工林生物量及碳储量研究. 内蒙古农业大学学报, 34(3), 49-53.]

Liu YQ (2012). The Study of Single Biomass, Carbon Storage and Distribution of Larix principis-rupprechtii and Populus in Hebei Province. Master degree dissertation, Agricultural University of Hebei, Baoding. 32-38. (in Chinese with English abstract) [刘亚茜 (2012). 河北地区华北落叶松、杨树单木生物 量、碳咜量及其分配规律. 硕士学位论文, 河北农业大学, 保定. 32-38.]

Jiang P, Ren JJ, Ren X, Cui H, Wang Q, Gu JC (2014). Biomass and carbon storage of Populus davidiana in typical theropencedrymion. Journal of Northwest Forestry University, 29, 15-20. (in Chinese with English abstract) [姜鹏, 任佳佳, 任仙, 崔浩, 王茜, 谷建才 (2014). 典型针阔混交林中山杨生物量 和碳储量研究. 西北林学院学报, 29, 15-20.]

Wang HY, Wang WJ, Qiu L, Su DX, An J, Zheng GY, Zu YG (2012). Differences in biomass, litter layer mass and SOC storage changing with tree growth in Larix gmelinii plantations in Northeast China. Acta Ecologica Sinica, 32, 833-843. (in Chinese with English abstract) [王洪岩, 王文杰, 邱岭, 苏冬雪, 安静, 郑广宇, 祖元刚 (2012). 兴安落叶松林生物量、地表枯落物量及土壤有机碳储量随林分生长的变化差异. 生态学报, 32, 833-843.]

Wang LM, Zhang QL, Yin JY (2003). Study on the growth pattern and bio-productivity of the Populus euphratica forest stand in Ejina. Journal of Arid Land Resources \& Environment, 17(2), 94-99. (in Chinese with English abstract) [王立明, 张秋良, 殷继艳 (2003). 额济纳胡杨林生长规律及生物生产力的 研究. 干旱区资源与环境, 17(2), 94-99.]

Wang XL, Chang Y, Chen HW, Hu YM, Jiao LL, Feng YT, Wu W, Wu HF (2014). Spatial pattern of forest biomass and its influencing factors in the Great Xing’an Mountains, Heilongjiang Province, China. Chinese Journal of Applied Ecology, 25, 974-982. (in Chinese with English abstract) [王晓莉, 常禹, 陈宏伟, 胡远满, 焦琳琳, 冯玉婷, 吴文, 伍海峰 (2014). 黑龙江省大兴安岭森林生物量空间格局及其影响因素. 应用生态学报, 25, 974-982.]

Xu ZQ, Li WH, Liu WZ, Wu XB (2006). Study on the biomass and productivity of Mongolian oak forests in northeast region of China. Chinese Journal of Eco-Agriculture, 14(3), 21-24. (in Chinese with English abstract) [许中旗, 李文华, 刘文忠, 吴雪宾 (2006). 我国东北地区蒙古栎林生物量及生产力 的研究. 中国生态农业学报, 14(3), 21-24.] 


\begin{tabular}{|c|c|c|}
\hline 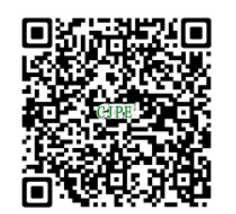 & 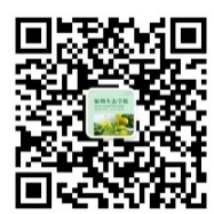 & 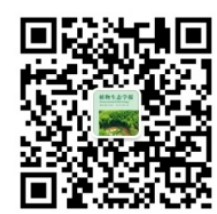 \\
\hline 植物生态学报官网 & & \\
\hline & $\begin{array}{l}\text { 期刊及学科 } \\
\text { 相关信息发布 }\end{array}$ & $\begin{array}{l}\text { 稿件状态查询 } \\
\text { 全文检索汶览 }\end{array}$ \\
\hline
\end{tabular}

